\title{
E-ABSENSI MAHASISWA FAKULTAS ILMU KOMPUTER UNIVERSITAS ALMUSLIM BERBASIS WEB
}

\author{
Fitriani $^{1)}$ dan Imam Muslem $\mathbf{R}^{2)}$ \\ ${ }^{1)}$ Mahasiswa Program Studi Informatika, Fakultas Ilmu Komputer, Universitas Almuslim Bireuen \\ ${ }^{2)}$ Dosen Program Studi Informatika, Fakultas Ilmu Komputer, Universitas Almuslim Bireuen \\ e-mail: fitri.ani.1234@gmail.com
}

\begin{abstract}
[Students Web-Based e-Attendance of Faculty of Computer Science Almuslim University] E-Attendance is a must for students. In doing attendance, they still use the manual method. Therefore, a student attendance system is needed that can collect data and manage data so that it can be done quickly, efficiently and accurately. Making the student attendance system is done by collecting data, system analysis, system design, and system implementation. This system is built using the PHP and MySQL programming languages for database management. As a result of this thesis is the creation of a web-based application of PHP-Based Student Attendance Information System using the web which has facilities such as: student data management, lecturer data management, course data management, attendance data management, and student attendance recap reports. With this application, it is hoped that the attendance process will be more efficient and can be easily monitored by lecturers and by the Head of Study Program.
\end{abstract}

Keywords: E-Attendance; Information System; MySQL; PHP; Students.

\begin{abstract}
Abstrak
E-Absensi merupakan hal yang wajib dilakukan untuk mahasiswa. Dalam melakukan absensi masih menggunakan cara manual. Oleh karena itu, diperlukan suatu sistem absensi mahasiswa yang dapat melakukan pendataan dan pengelolaan data agar dapat dilakukan secara cepat, efisien, dan akurat. Pembuatan sistem absensi mahasiswa ini dilakukan dengan cara pengumpulan data, analisa sistem, perancangan sistem, dan implementasi sistem. Sistem ini dibuat dengan menggunakan bahasa pemrograman PHP dan MySQL untuk pengelolaan database. Sebagai hasil dari Skripsi ini adalah dibuatnya aplikasi berbasis web Sistem Informasi Absensi Mahasiswa Berbasis PHP Menggunakan web yang memiliki fasilitas seperti: manajemen data mahasiswa, manajemen data dosen, manajemen data mata kuliah, manajemen data absensi, dan laporan rekap absensi mahasiswa. Dengan adanya aplikasi ini, diharapkan proses absensi akan lebih efisien dan dapat dipantau dengan mudah oleh dosen dan oleh Ka.Prodi.
\end{abstract}

Kata Kunci: E-Absensi; Mahasiswa; MySQL; PHP; Sistem Informasi.

\section{Pendahuluan}

Universitas Almuslim Peusangan Bireuen Provinsi Aceh didirikan pada Tanggal 21 Jumadil akhir 1348 H, bertepatan dengan tanggal 24 Nopember 1929 M (Ismail, 2017). Pada mulanya bernama Jami'ah Almuslim, dengan tokoh pendirinya Tgk. Abdurrahman Meunasah Meucap, Tgk. Chiek Muhammad Djohan Alamsyah (Ulee Balang Peusangan), Tgk. H. Ibrahim Meunasah Barat, Tgk. Abbas Bardan, Tgk. Abed Idham, Habib Muhammad, Tgk. Ridwan dan Lain-lain (Idrus, Agustono, \& Nuhung, 2020; Ismail, 2017). Universitas Almuslim pada usia ke 12 tahun memiliki 8.149 Mahasiswa aktif, telah mewisudakan 18.239 Sarjana, memiliki 517 orang dosen yang sebagian bergelar Magister dan Doktor, 250 orang tenaga Administrasi dan Tenaga Perbantuan Lainnya.

Dosen adalah pendidik profesional dan ilmuwan dengan tugas utama mentransformasikan, mengembangkan, dan menyebarluaskan ilmu pengetahuan, teknologi, dan seni melalui pendidikan, penelitian, dan pengabdian kepada masyarakat (Andoyo, Muslihudin, \& Sari, 2017; Sofhian, Sujaini, \& Pratiwi). Dalam menjalankan tugasnya dosen memiliki kewajiban dan hak. Kewajiban dosen yaitu meningkatkan kualitas proses belajar dan mengajar sedangkan hak dosen antara lain memperoleh gaji pokok (Kusnan, 2018; Yaqin, 2017; Yudi \& 
Surbakti, 2020). Sistem absensi dosen yang baik berpengaruh besar terhadap kelancaran kegiatan belajar mengajar yang nantinya diharapkan dapat meningkatkan kualitas proses belajar dan mengajar (Sari \& Suardana, 2017).

Absensi memegang peranan penting dalam setiap kegiatan terjadwal di setiap instansi. Oleh karena itu, absensi merupakan salah satu penunjang yang dapat mendukung atau memotivasi setiap kegiatan yang dilakukan di dalamnya. Di samping itu, absensi juga sebagai informasi tentang kedisiplinan seorang karyawan/pegawai pada suatu intansi bersangkutan (Ferdika \& Nasution, 2020). Maka dari itu penulis berkeinginan untuk merancang suatu sistem informasi absensi yang bersifat digital (Aini, Graha, \& Zuliana, 2017; Enggari \& Darman, 2017). Sistem ini merupakan sistem komputerisasi yang dirancang dengan menggunakan bahasa pemrograman PHP dan database MySQL berbasis website.

Berdasarkan survei yang dilakukan, sistem absensi yang berjalan saat ini kurang efektif dan efisien dalam proses pemakaiannya. Hal ini disebabkan oleh sistem absensi yang dilakukan secara manual dan dikerjakan dalam buku agenda absensi yang ada di kantor pengajaran atau kantor program studi. Pemakaian sistem absensi seperti ini pun menimbulkan bermasalahan, yaitu buku agenda absensi dosen mudah rusak dan kotor, masalah yang paling mendasar adalah buku agenda ini mudah hilang, sehingga menghambat rekapitulasi kehadiran mahasiswa sehingga hal ini dianggap kurang baik dan kurang profesional. Oleh karena itu, penulis ingin mengembangkan sistem absensi mahasiswa yang saat ini dipakai secara manual menjadi sistem absensi yang berbasis Web yang dapat menghasilkan Informasi yang lebih efektif dan efisien (Rotikan, 2016).

\section{Metode}

Adapun tahap - tahap yang dilalui dalam penelitian ini adalah sebagai berikut:

1. Tahap analisis, bertujuan untuk memahami pemecahan masalah.

2. Tahap desaign, bertujuan untuk memahami pemecahan masalah yang di dapat pada tahap analisis melalui suatu pemodelan.

3. Tahap implementasi, untuk menerapkan pemodelan yang telah di buat menjadi sistem aplikasi sesungguhnya.

4. Coding, tahap penerjemahan data atau pemecahan masalah yang telah dirancang ke dalam bahasa pemrograman tertentu.

5. Pengujian, merupakan tahap pengujian terhadap perangkat lunak yang dibangun.

6. Maintenance (Pemeliharaan), tahap ini merupakan tahap akhir dimana perangkat lunak yang telah selesai diimplementasikan dapat terjadi perubahan-perubahan.

\section{Hasil dan Pembahasan}

\section{A. Perancangan Sistem}

Perancangan sistem merupakan suatu kegiatan pengembangan prosedur dan proses yang sedang berjalan untuk menghasilkan suatu sistem yang baru, atau memperbaharui sistem yang ada untuk meningkatkan efektifitas kerja agar dapat memenuhi hasil yang digunakan dengan tujuan memanfaatkan teknologi dan fasilitas yang tersedia. Pada bagian ini penyusun akan memberikan usulan yang merupakan sistem informasi secara komputerisasi yang diharapkan akan membantu dan mempermudah pekerjaan.

\section{Diagram Kontek}

Diagram Konteks berfungsi untuk menggambarkan sistem secara keseluruhan yang diwakili oleh suatu lingkaran yang mewakili seluruh proses yang terjadi, juga menggambarkan bagaimana hubungan antara sistem dan entitas yang terlibat. Berikut adalah gambar dari Diagram Konteks E-Absensi Mahasiswa Fakultas Ilmu Komputer Universitas Almuslim Berbasis Web. 


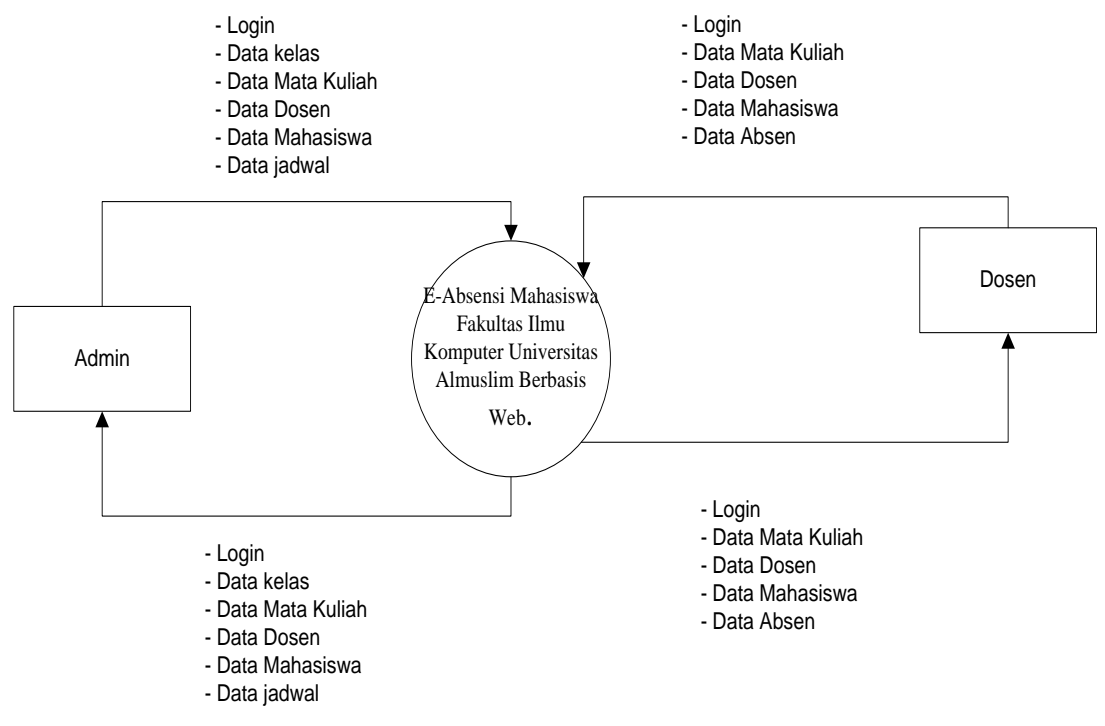

Gambar 1. Diagram Konteks E- Absensi Mahasiswa

2. ERD (Entity Relationship Diagram)

Entity Relationship Diagram E-Absensi Mahasiswa Fakultas Ilmu Komputer Universitas Almuslim Berbasis Web.dapat dilihat pada gambar dibawah ini :

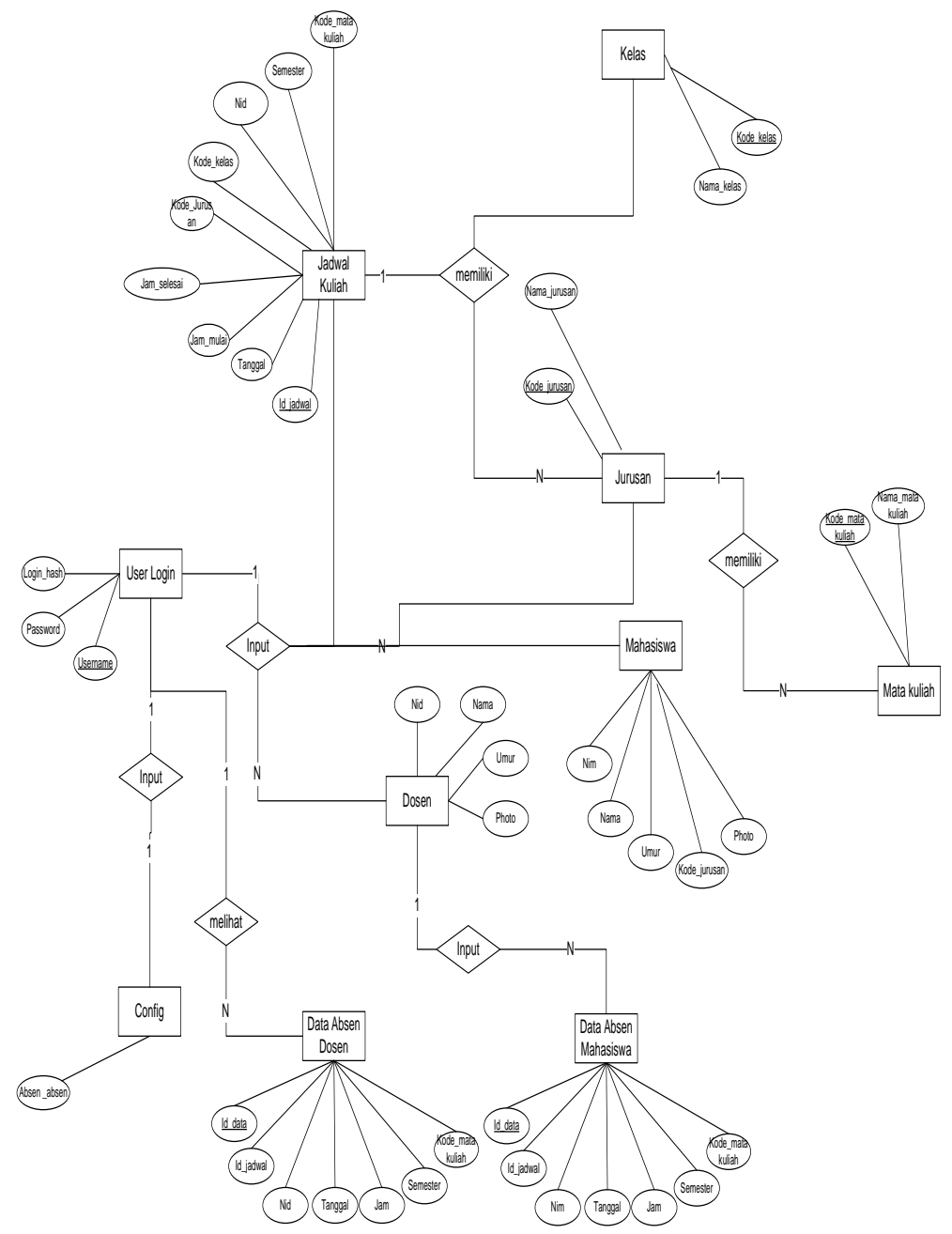

Gambar 2. Entity Relationship Diagram 
B. Implementasi

Struktur menu E-Absensi Mahasiswa Fakultas Ilmu Komputer Universitas Almuslim Berbasis Web adalah sebagai berikut:

1. Login Administrator

Halaman ini merupakan halaman login administrator untuk masuk ke dalam sistem dengan memasukkan username dan password, jika username dan password yang dimasukkan valid maka admin masuk ke sistem dan jika username dan password yang dimasukkan tidak valid makan admin harus login kembali. Berikut tampilan halaman login administrator.

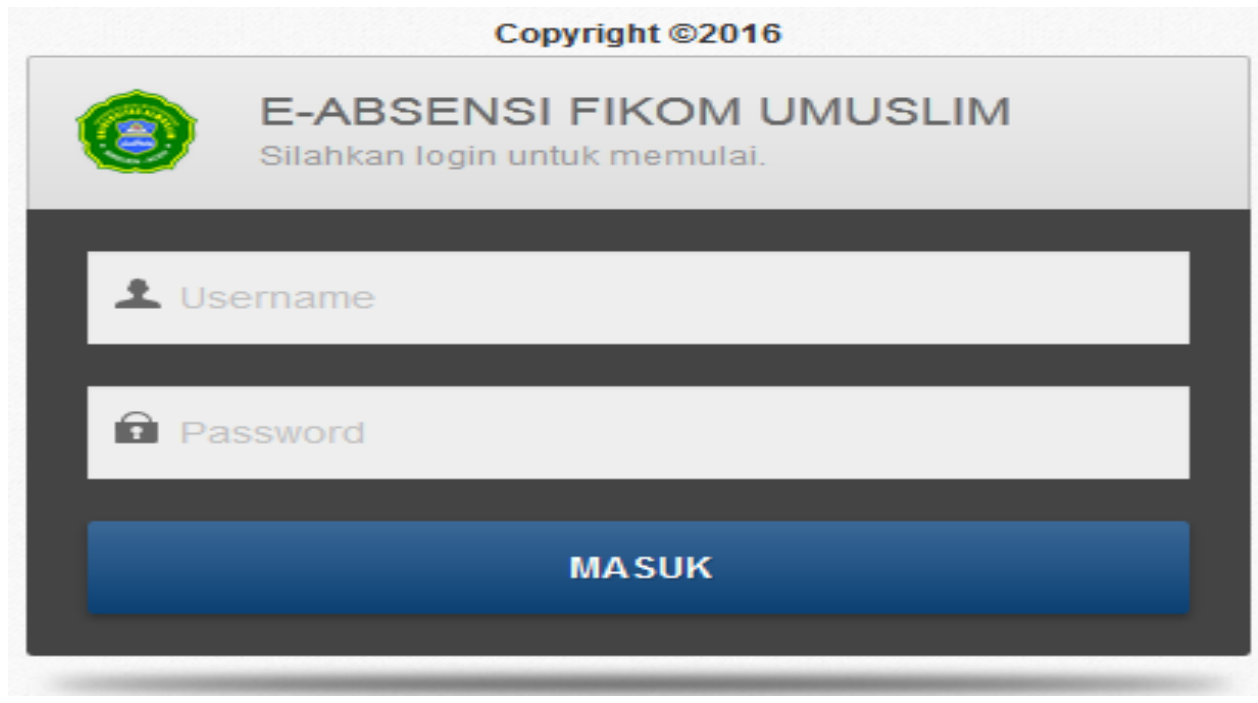

Gambar 3. Tampilan Halaman Login Adminitrator

Penjelasan Form Login Administrator
a. Username
: Diisi dengan username admin sesuai dengan isi didatabase
b. Password
: Diisi dengan password admin sesuai dengan isi didatabase
c. Button Login
: Fungsinya untuk proses login admin

2. Halaman Utama Admin

Halaman ini merupakan halaman index admin. Pada halaman ini ditampilkan selamat datang admin, dan ada beberapa menu antara lain yaitu : menu dasboard, menu mahasiswa, menu dosen, menu kelas, menu jadwal, menu mata kuliah, menu laporan dan menu logout. Berikut tampilan halaman utama admin.

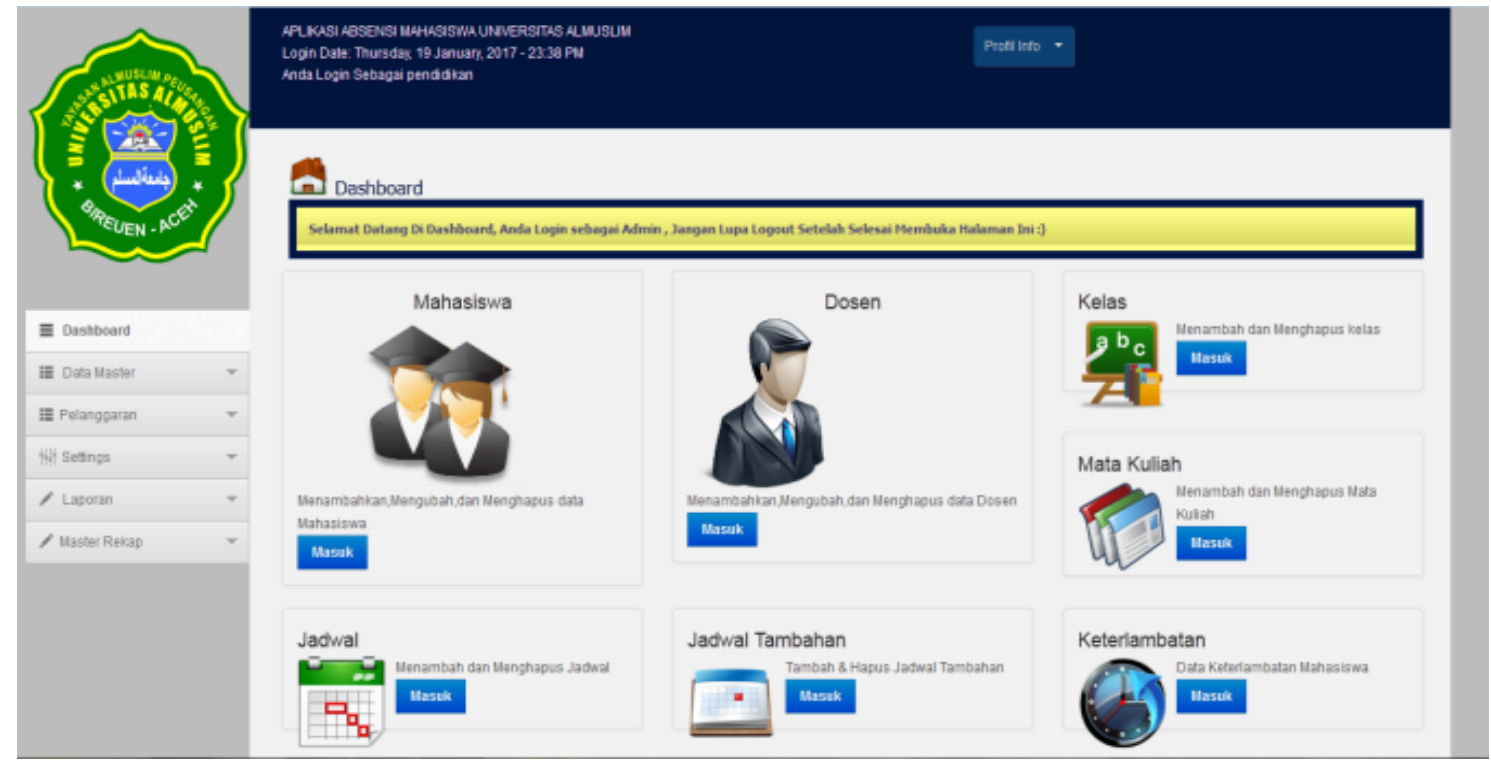

Gambar 4. Tampilan Halaman Utama Admin 
3. Halaman Data Mahasiswa

Halaman ini merupakan halaman yang menampilkan data mahasiswa yang ditampilkan dalam sebuah tabel juga memiliki tombol edit dan hapus. Berikut tampilan halaman data mahasiswa.

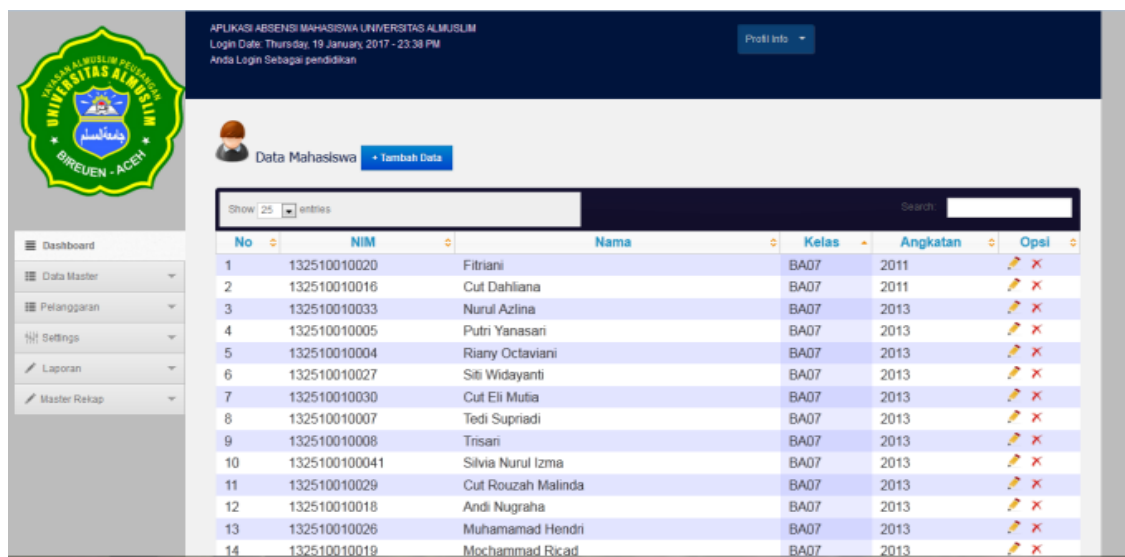

Gambar 5. Tampilan Halaman Data Mahasiswa

4. Halaman Input Data Mahasiswa

Halaman ini merupakan halaman untuk proses input data mahasiswa yang di input admin setelah berasil melakukan login. Pada halaman ini tersedia sebuah form input data dengan beberapa field. Untuk lebih jelas dapat dilihat pada gambar berikut.

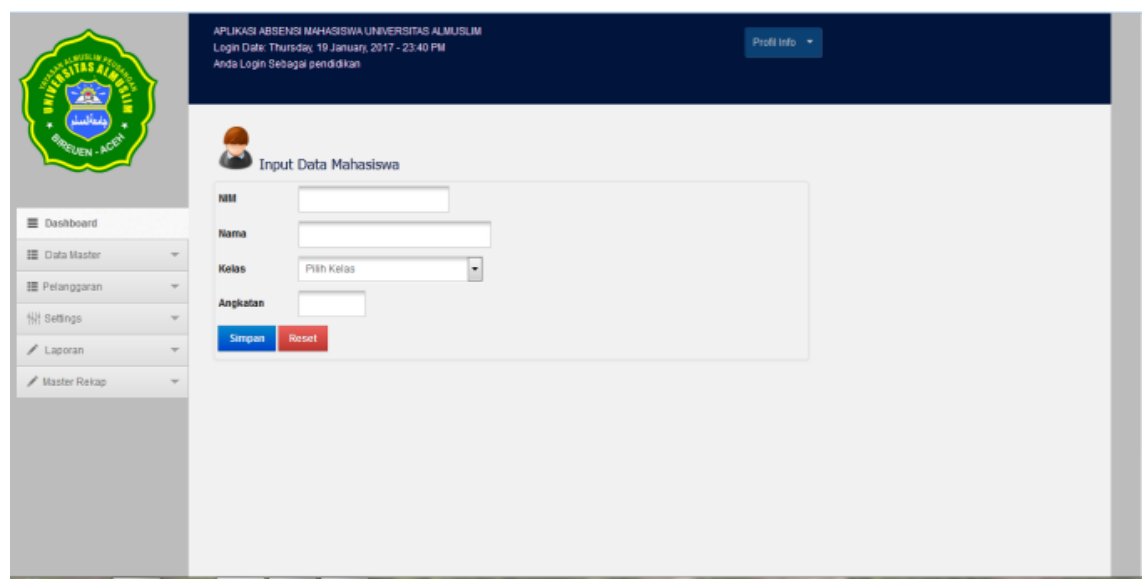

Gambar 6. Tampilan Halaman Input Data Mahasiswa

5. Halaman Data Dosen

Halaman ini merupakan halaman yang menampilkan data dosen yang ditampilkan dalam sebuah tabel juga memiliki tombol edit dan hapus. Berikut tampilan halaman data dosen.

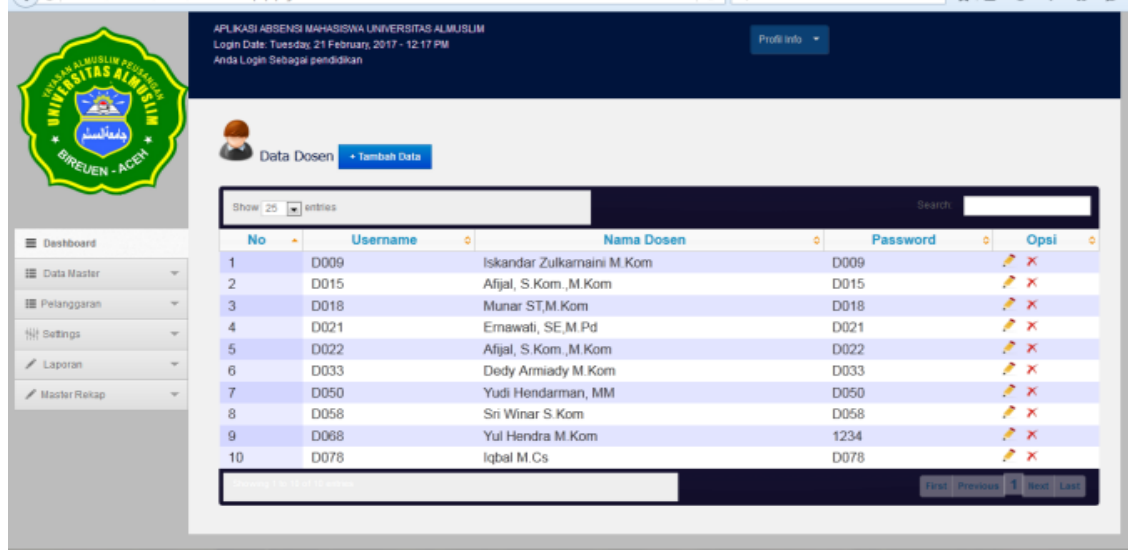

Gambar 7. Tampilan Halaman Data Dosen 
6. Halaman Input Data Dosen

Halaman ini merupakan halaman untuk proses input data dosen yang di input admin setelah berasil melakukan login. Pada halaman ini tersedia sebuah form input data dengan beberapa field. Untuk lebih jelas dapat dilihat pada gambar berikut.

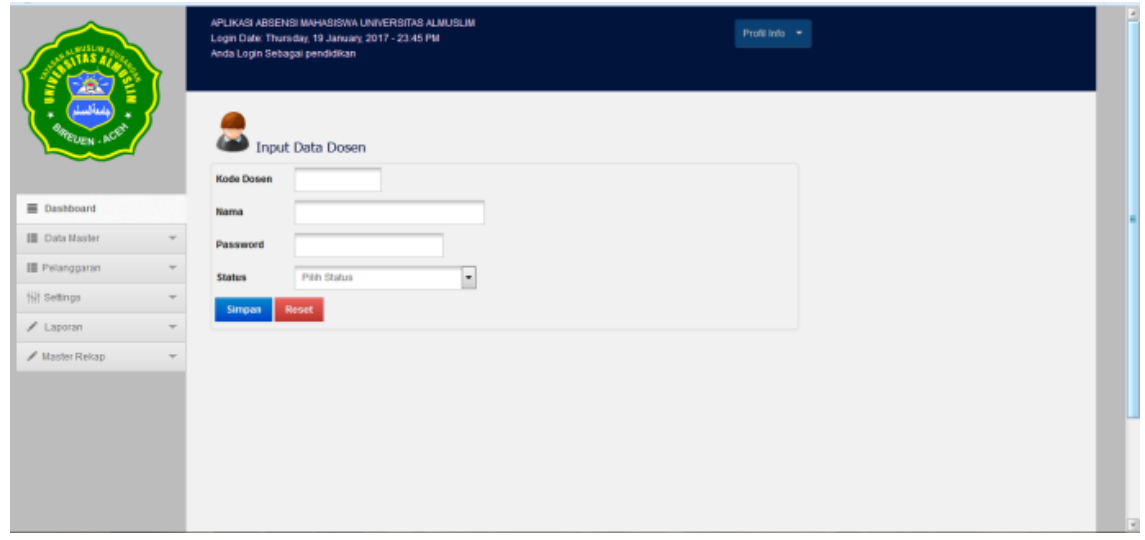

Gambar 8. Tampilan Halaman Input Data Dosen

7. Halaman Input Data Kelas

Halaman ini merupakan halaman untuk proses input data kelas yang di input admin setelah berasil melakukan login. Pada halaman ini tersedia sebuah form input data dengan beberapa field. Untuk lebih jelas dapat dilihat pada gambar berikut.

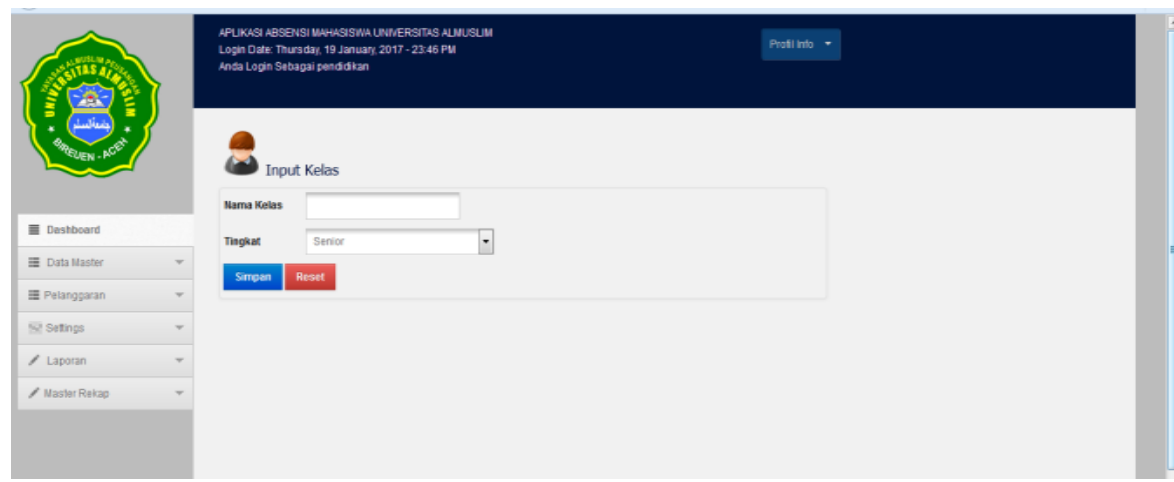

Gambar 9. Tampilan Halaman Input Kelas

8. Halaman Data Mata Kuliah

Halaman ini merupakan halaman yang menampilkan data mata kuliah yang ditampilkan dalam sebuah tabel juga memiliki tombol edit dan hapus. Berikut tampilan halaman data mata kuliah.

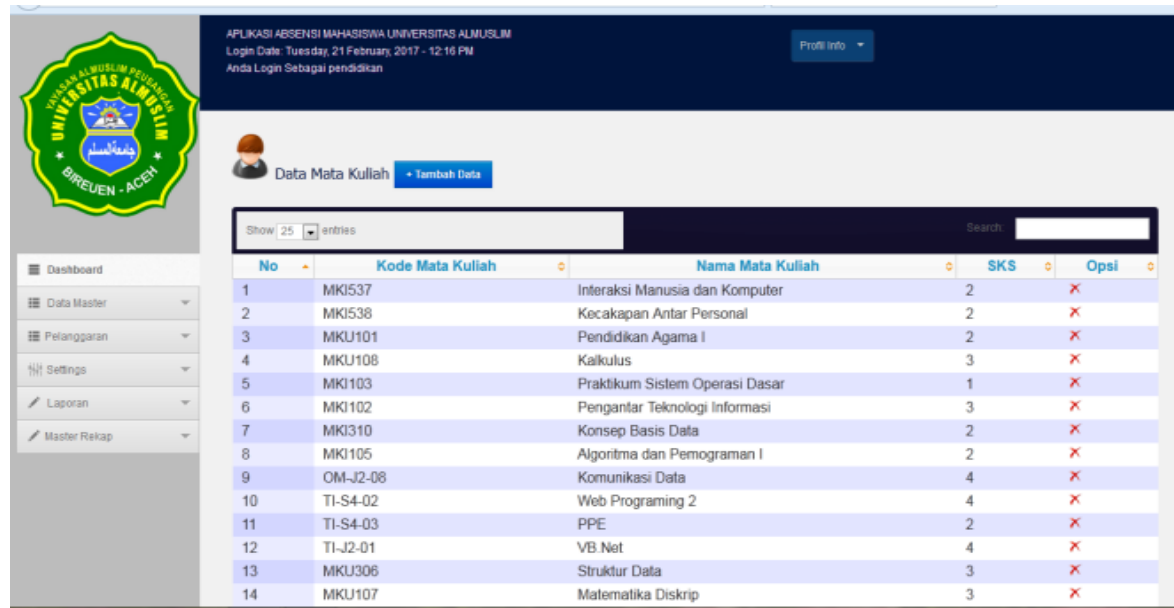

Gambar 10. Tampilan Halaman Data Mata Kuliah 
9. Halaman Input Data Mata Kuliah

Halaman ini merupakan halaman untuk proses input data data mata kuliah yang di input admin setelah berasil melakukan login. Pada halaman ini tersedia sebuah form input data dengan beberapa field. Untuk lebih jelas dapat dilihat pada gambar berikut.

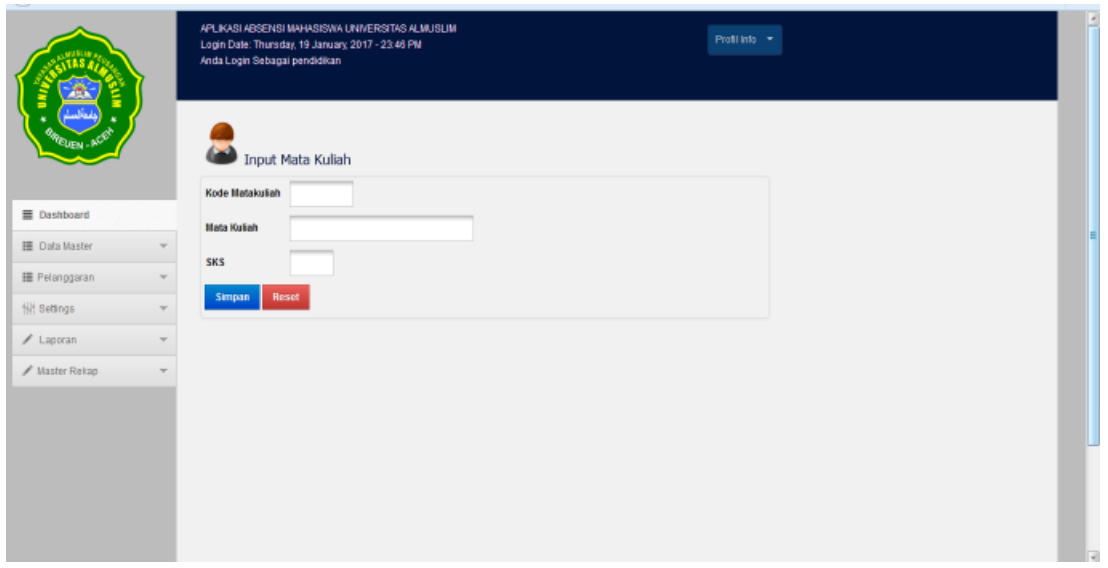

Gambar 11. Tampilan Halaman Input Data Mata Kuliah

10. Halaman Data Jadwal Kuliah

Halaman ini merupakan halaman yang menampilkan data jadwal kuliah yang ditampilkan dalam sebuah tabel juga memiliki tombol edit dan hapus. Berikut tampilan halaman data jadwal kuliah.

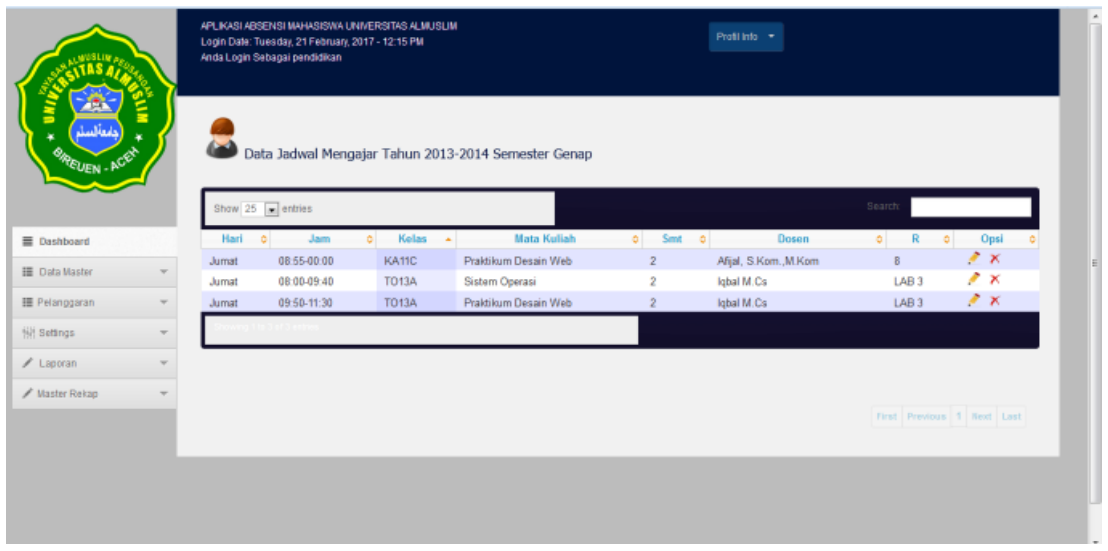

Gambar 12. Tampilan Halaman Data Jadwal

\section{Kesimpulan}

Berdasarkan uraian pembahasan analisis dan pengujian yang telah dilakukan, maka dapat diambil kesimpulan terhadap pembangunan E-Absensi Mahasiswa Fakultas Ilmu Komputer Universitas Almuslim Berbasis Web, yaitu sebagai berikut:

1. Pembangunan media berbasis website ini memudahkan bagi pengakses website baik itu admin sebagai pengelola web maupun user umum untuk memperoleh informasi absensi kehadiran mahasiswa.

2. Website yang telah dibangun dapat memberikan informasi penomeran index yang sesuai dengan aturan Fakultas.

3. Aplikasi website yang telah dibangun ini berhasil menampilkan berapa info seperti mahasiswa, data dosen, jadwal, absensi dan info lainya, dengan ini adanya keterbukaan dari pihak Fakultas Ilmu Komputer dalam penyampaian informasi

\section{Daftar Pustaka}

Aini, Q., Graha, Y. I., \& Zuliana, S. R. (2017). Penerapan Absensi QRCode Mahasiswa Bimbingan Belajar pada Website berbasis YII Framework. Sisfotenika, 7(2), 207-218.

Andoyo, A., Muslihudin, M., \& Sari, N. Y. (2017). Pembuatan Model Penilaian Indeks Kinerja Dosen Menggunakan Metode Fuzzy Multi Attribute Decision Making (FMADM)(Studi: PTS di Provinsi Lampung). Paper presented at the Prosiding Seminar Nasional Darmajaya. 
Enggari, S., \& Darman, D. (2017). Perancangan Sistem Informasi Absensi Siswa MTsN Pariaman Selatan Dengan Menggunakan PHP MySQL dan SMS GateWay. TEKNOLOGI, 6(1).

Ferdika, R., \& Nasution, R. D. (2020). PERUBAHAN ORIENTASI MOTIVASI PEGAWAI PADA PENERAPAN E-ABSENSI DI KABUPATEN PONOROGO CHANGES IN ORIENTATION OF EMPLOYEE MOTIVATION IN THE APPLICATION OF E-ABSENSI IN PONOROGO DISTRICT. Jurnal Penelitian Komunikasi dan Opini Publik Vol, 24(1), 71-84.

Idrus, I., Agustono, B., \& Nuhung, N. (2020). Modernisasi Dayah Darul Huda Kota Langsa, 1962-2005. MUKADIMAH: Jurnal Pendidikan, Sejarah, dan Ilmu-ilmu Sosial, 4(2), 108-118.

Ismail, A. (2017). TEUNGKU ABDURRAHMAN MEUNASAH MEUCAP: STUDY BIOGRAFI DAN PEMIKIRAN BIDANG PENDIDIKAN. Kalam: Jurnal Agama dan Sosial Humaniora, 5(2).

Kusnan, K. (2018). Kebijakan Mutu Peningkatan Dosen. Jurnal Ilmiah Iqra', 11(2).

Rotikan, R. (2016). Sistem Informasi Absensi Berbasis Web Untuk Kegiatan Konferensi. Sisfotenika, 6(1), 4655 .

Sari, I. W., \& Suardana, I. B. R. (2017). Dampak penerapan absensi fingerprint terhadap implementasi fungsi manajemen dan kinerja. Jurnal Manajemen Bisnis, 14(2), 111-128.

Sofhian, S., Sujaini, H., \& Pratiwi, H. S. Sistem Pendukung Keputusan Pemilihan Dosen Terbaik Menggunakan Metode Promethee (Studi Kasus: Teknik Informatika Universitas Tanjungpura). JUSTIN (Jurnal Sistem dan Teknologi Informasi), 4(2), 316-321.

Yaqin, I. (2017). Perlindungan Hukum bagi Dosen sebagai Tenaga Pendidik untuk Memperoleh Hak Ketenagakerjaannya. Dialogia Iuridica: Jurnal Hukum Bisnis dan Investasi, 8(2), 24-41.

Yudi, P., \& Surbakti, K. (2020). PERLINDUNGAN HUKUM HAK DAN KEWAJIBAN DOSEN TERHADAP INTERVENSI YAYASAN PADA PERGURUAN TINGGI. JURNAL EKONOMI, SOSIAL \& HUMANIORA, 2(03), 85-91. 